\title{
Estudos biométricos em frutos, sementes e germinação de matapasto (Senna
}

\section{reticulata) da Amazônia}

Biometric studies in fruits, seeds and germinatio of matapasto (Senna reticulata) from Amazonia

Estudios biométricos en frutos, semillas y germinación de el matapasto (Senna reticulata) de la Amazonía

Recebido: 16/12/2021 | Revisado: 24/12/2021 | Aceito: 29/12/2021 | Publicado: 30/12/2021

Jonilson Ribeiro Trindade
ORCID: https://orcid.org/0000-0003-1540-6284
Museu Paraense Emílio Goeldi, Brasil
E-mail: jonilsonrt@gmail.com
Cleidiane Alves Rodrigues
ORCID: https://orcid.org/0000-0001-9107-1100
E-mail: cleidiane_10@ @otmail.com
Universidade Estadual do Norte Fluminense Darcy Ribeiro, Brasil
João Ubiratan Moreira dos Santos
ORCID: https://orcid.org/0000-0001-9850-0334
Universidade Federal Rural da Amazônia, Brasil
E-mail: bira@ museu-goeldi.br
Ely Simone Cajueiro Gurgel
ORCID: https://orcid.org/0000-0002-9488-7532
Museu Paraense Emílio Goeldi, Brasil
E-mail: esgurgel@ @useu-goeldi.br

\begin{abstract}
Resumo
A Senna reticulata (Willd.) H.S.Irwin \& Barneby é uma planta nativa da Amazônia e conhecida popularmente como "matapasto" ou "folha de pajé", é pioneira em áreas abertas, possui usos alimentícios, medicinais, paisagísticos e outros. Para essa espécie, assim como diversas outras do bioma Amazônia, há carência de informações sobre os aspectos biométricos de seus frutos e de seu desenvolvimento inicial desde as sementes, sendo que tais informações são úteis para a identificação e manejo. Sendo assim, o presente trabalho realizou tal estudo, através da coleta de propágulos (frutos e sementes) diretamente da copa de árvores localizadas na cidade de Belém do Pará, na Amazônia. Foram analisadas 100 unidades de frutos e sementes no estudo das variáveis biométricas: comprimento, largura, espessura, desvio padrão $(\sigma)$ e coeficiente de variação (CV). Bem como, também foram analisadas 100 unidades para caracterização de germinação. Os frutos apresentaram médias de 12,96 cm de comprimento; $1,45 \mathrm{~cm}$ de largura.; 0,22 $\mathrm{cm}$ de espessura; e média de 33 sementes por fruto. As sementes apresentam médias de $6,42 \mathrm{~mm}$ de comprimento.; $2,32 \mathrm{~mm}$ de largura; e $1,74 \mathrm{~mm}$ de espessura. O teor de umidade foi de $9,9 \%$, já o peso de mil sementes foi de $19 \mathrm{~g}$. A germinação começa a partir do $2^{\circ}$ dia de plantio, do tipo fanerocotiledonar e a planta jovem forma-se a partir dos 33 dias, alcançado assim fase ideal para seu cultivo.
\end{abstract}

Palavras-chave: Biodiversidade; Desenvolvimento; Folha de Pajé; Leguminosae.

\begin{abstract}
Senna reticulata (Willd.) H.S.Irwin \& Barneby is a plant that is native from the Amazonia rain forest, and popularly known as "matapasto" or "shaman's leaf", is a pioneer in open areas, also has food, medicinal, landscape and other uses. For this species, as well as several others from the Amazonia's biome, there is a lack of information about the biometric aspects of its fruits and its initial development from the seeds, and such information is useful for identification and management. Thus, the present work carried out such a study, through the collection of propagules (fruits and seeds) directly from the canopy of trees located in the city of Belém from Pará, in the Amazonia. One hundred units of fruits and seeds were analyzed in the study of biometric variables: length, width, thickness, standard deviation $(\sigma)$ and coefficient of variation (CV). The fruits had averages of $12.96 \mathrm{~cm}$ length; $1.45 \mathrm{~cm}$ wide; $0.22 \mathrm{~cm}$ in thickness; and an average of 33 seeds per fruit. The seeds have an average of $6.42 \mathrm{~mm}$ length; $2.32 \mathrm{~mm}$ wide; and $1.74 \mathrm{~mm}$ thick. The water content was $9.9 \%$, while the weight of a thousand seeds is $19 \mathrm{~g}$. As well, 100 units were also analyzed in the germination characterization. The germination begins from the 2nd day of planting, it's phanerocotyledonar type, and the young plant forms after 33 days, thus reaching the ideal stage for its cultivation.
\end{abstract}

Keywords: Biodiversity; Development; Shaman's leaf; Leguminosae. 


\begin{abstract}
Resumen
Senna reticulata (Willd.) H.S. Irwin \& Barneby es una planta de la Amazonía y conocida popularmente como "matapasto" o "hoja de shamán", es pionera en áreas abiertas, tiene usos alimenticios, medicinales, paisajísticos y otros. Para esta especie, así como para varias otras de la Amazonía, falta informacións sobre los aspectos biométricos de sus frutos y su desarrollo inicial a partir de las semillas, informacións útil para la identificación y manejo. El presente trabajo realizó estudio mediante la recolección de propágulos (frutos y semillas) directamente del dosel de árboles ubicados en la ciudad de Belém do Pará, Amazonía. Entonces 100 unidades de frutos y semillas se analizaron el aspectos biométricas: largo, ancho, grosor, desviación estándar $(\sigma)$ y coeficiente de variación $(\mathrm{CV})$. Además, también se analizaron 100 unidades en la caracterización de la germinación. Los frutos tuvieron promedios de 12,96 $\mathrm{cm}$ de largo; $1,45 \mathrm{~cm}$ de ancho; 0,22 $\mathrm{cm}$ de espesor y un promedio de 33 semillas por fruto. Las semillas tienen un promedio de 6,42 $\mathrm{mm}$ de largo, 2,32 $\mathrm{mm}$ de ancho y 1,74 $\mathrm{mm}$ de espesor. El contenido de humidad fue del 9,9\%, mientras que el peso de mil semillas es de $19 \mathrm{~g}$. La germinación comienza a partir del $2^{\circ}$ día de siembra, ere del tipo fanerocotiledóneo, mientras que la planta joven se forma a los 33 días, alcanzando así la etapa ideal para su cultivo.

Palabras clave: Biodiversidad; Desarrollo; Hoja de Shamán; Leguminosae.
\end{abstract}

\title{
1. Introdução
}

A Amazônia é uma das áreas com a maior biodiversidade do planeta, no entanto, apesar de sua importância, ainda há uma grande lacuna no conhecimento desta, especialmente em se tratando de plantas (Forzza et al., 2012). Inserido neste contexto, o Brasil abriga a maior biodiversidade do planeta, com uma abundante variedade de organismos, que se traduz em mais de 20\% do número total de espécies (IBGE, 2014; MMA, 2021).

O gênero Senna Mill. pertence à família Fabaceae Lindl. (Leguminosae), no mundo composto por cerca de 350 espécies, e no Brasil ocorrem cerca de 80 destas (Irwin \& Barneby, 1982; Silva et al., 2018). Segundo Rodrigues (1989), espécies de Senna Mill. também são conhecidas na região como “folha de pajé”, devido suas propriedades e usos por diversas populações tradicionais da região, que utilizam suas folhas para cicatrização de feridas, as sementes como vermífugas e as raízes como tônicas. Ou seja, praticamente todas as partes destes vegetais apresentam usos, sendo assim necessários maiores estudos para o melhor conhecimento de suas propriedades e manejo destas.

A Senna reticulata (Willd.) H.S. Irwin \& Barneby é uma espécie vegetal nativa da Amazônia Oriental, segundo sua descrição original feita por Willdenow (1809) ainda como Cassia reticulata Willd., e posterior revisão por Irwin e Barneby (1982) que a transferiram para o gênero Senna Mill. Atualmente a espécie ocorre desde o México até a Bolívia (Souza, 2012; Tropicos, 2021). No Brasil encontra-se distribuída por praticamente todo o território, exceto nos estados da Região Sul (Souza \& Bortoluzzi, 2021; Silva et al., 2018).

A S. reticulata é conhecida popularmente como "matapasto" desde muito tempo pelas populações da Amazônia (Willdenow, 1809; Irwin \& Barneby, 1982). Há diversos registros do uso de matapasto (S. reticulata) na medicina tradicional amazônica, onde as partes do vegetal utilizadas variam conforme o tratamento (Di Stasi \& Hiruma-Lima, 2002; Neves et al., 2017). Bem como a espécie também apresenta comprovação científica para propriedades antifúngica, antimalárica e antioxidante (Macedo et al., 2016; Santos et al., 2008). A rica e diversificada flora amazônica representa um excelente recurso de novas estruturas químicas com atividades biológicas (Gurgel et al., 2019). Sendo que, a utilização de espécies vegetais em uma alimentação natural e como plantas medicinais, são alternativas viáveis para o tratamento de diversas doenças (FAO, 2021; Lorenzi \& Matos, 2021).

Além disso, o matapasto (S. reticulata) também poder se utilizado como planta ornamental (Di Stasi \& Hiruma-Lima, 2002; Prance, 1975). E, segundo Parolin (2001), por seu crescimento rápido e fácil adaptação em planícies inundadas, o matapasto ( $S$. reticulata) é considerada uma planta pioneira de áreas abertas da planície Amazônica. Bem como Grandis et al. (2021), indicam que a espécie pode ser uma fonte viável de biocombustível. No Brasil para fins energéticos, historicamente utiliza-se espécies do gênero Eucalpyptus L'Hér., que apesar de seu rápido desenvolvimento com algumas espécies alcançado porte ideal em poucos anos, são plantas exóticas (Coelho Junior et al., 2020). O matapasto (S. reticulata) além de ser uma 
espécie nativa, apresenta índices de crescimento superiores até aos de Eucalyptus, pois segundo Falcão-da-Silva et al. (2016) a partir de sua germinação com apenas 9 meses a espécie já alcança até $3 \mathrm{~m}$ de altura, e antes de 1 ano já flora e produz sementes.

Estudos sobre frutos, sementes, plântulas e plantas jovens são de grande importância, pois fornecem informações sobre particularidades que dão suporte para a identificação e diferenciação de espécies próximas ainda em campo, bem como auxiliam em ações de manejo e cultivo destas (Camargo et al., 2008; Deuber, 2003; Farias et al., 2007; Moura et al., 2010; Rodrigues et al., 2015; Silva et al., 2016).

Haja vista que, devido ao avanço do desflorestamento na Amazônia nos últimos anos, as perspectivas são alarmantes. Segundo o estudo de Gomes et al. (2019) caso medidas diretas não sejam tomadas até o ano de 2050, a floresta amazônica pode entrar em um nível de declínio irreparável. Sendo que, o cultivo de uma espécie arbórea de rápido crescimento e diversos usos como o matapasto (S. reticulata) pode auxiliar em ações de reflorestamento na Amazônia, e até em outras regiões. O objetivo deste estudo foi determinar características biométricas, descrever a morfologia de frutos, sementes e do desenvolvimento pós-seminal até a fase de planta jovem do matapasto ( $S$. reticulata), a fim de fornecer informações que possam auxiliar em seu cultivo e manejo.

\section{Metodologia}

Para esta pesquisa realizaram-se coletas de material botânico de matapasto (S. reticulata) de acordo com técnicas em taxonomia vegetal (Martins-da-Silva et al., 2014), no período de 2018 até 2020, na Região Metropolitana de Belém, estado do Pará, Amazônia Oriental, Brasil. Para este trabalho foram selecionadas matrizes, depositadas através de exsicatas para registro no acervo do Herbário do Museu Paraense Emílio Goeldi (MG), sob os números de registro MG 233280 e MG 233276.

Estruturas de propágulos (frutos e sementes) foram coletadas diretamente da copa das árvores matrizes (Figura 1), e mantidas em temperatura ambiente, e posteriormente selecionadas 100 amostras cada, das variáveis biométricas: comprimento (compr.), largura (larg.), espessura (esp.), desvio padrão $(\sigma)$ e coeficiente de variação (CV). Bem como demais procedimentos metodológicos para biometria de frutos e sementes estão de acordo com o estudo de Gurgel et al. (2014), que avaliou parâmetros biométricos de frutos e sementes para outras três espécies do gênero Senna Mill. (S. obtusifolia, S. occidentalis e $S$. tapajozensis).

Posteriormente, foram selecionados frutos e sementes considerados sadios, ou seja, sem sinais visuais da presença de fitopatógenos (bactérias, fungos, insetos e outros), para determinação do peso de mil sementes e demais observações pertinentes, segundo as literaturas de referência do Ministério da Agricultura Pecuária e Abastecimento (MAPA) do Brasil: Glossário ilustrado de morfologia (Brasil, 2009a), Instruções para análise de sementes de espécies florestais (Brasil, 2013), Manual de análise sanitária de sementes (Brasil, 2009b) e Regras para análise de sementes (Brasil, 2009c). Para a determinação do teor de umidade das sementes foi utilizado o aparelho medidor de umidade com fonte de calor infravermelho.

Para a análise da germinação foram utilizadas quatro repetições com 25 sementes, totalizando 100 unidades a serem analisadas, em baldes plásticos reciclados de $20 \mathrm{~cm}$ x $18 \mathrm{~cm}$ x $18 \mathrm{~cm}$, dispostas à aproximadamente $1 \mathrm{~cm}$ de profundidade. $\mathrm{O}$ substrato utilizado foi areia lavada, sem adição de qualquer produto químico para alteração de desenvolvimento, bem como as demais condições para o experimento foram de ambiente aberto da região, conforme recomendado por Albuquerque (1993), que estabeleceu parâmetros para análise da germinação e desenvolvimento de espécies amazônicas.

Para descrever aspectos biométricos e morfológicos de matapasto (S. reticulata) foram consideradas características externas e internas de frutos, sementes e estruturas presentes nas etapas do desenvolvimento pós-seminal até a formação da planta jovem com auxílio de paquímetro e balança digital, ambos considerando valores com duas casas decimais. Os 
parâmetros morfológicos analisados, descritos e a nomenclatura, está de acordo com Albuquerque (1993); Barroso et al. (1999); Brasil (2009a); Brasil (2009b); Brasil (2009c); Camargo et al. (2008); Gurgel (2009) e Mourão et al. (2007). Bem como, foram feitas algumas modificações, quando necessárias, devido ainda não constar informações específicas para este vegetal nas literaturas.

Figura 1. Matapasto (S. reticulata) utilizada como planta ornamental na Região Metropolitana de Belém, Amazônia Oriental.



Fonte: Autores.

\section{Resultados e Discussão}

\section{Biometria de frutos}

A espécie apresentou fruto do tipo legume (Figura 2A) conforme indicou Barroso et al. (1999) ser este o tipo comum para o grupo, bem como observou Gurgel et al. (2014) ser este o padrão para outras espécies do gênero Senna. No entanto também observou a ocorrência de fruto do tipo folículo em Senna tapajozensis (Ducke) H.S.Irwin \& Barneby, sendo assim é importante serem realizadas descrições para melhor caracterização e compreensão das espécies deste grupo, pois podem haver variações. A coloração do fruto é verde quando imaturo, e maduro passa de marrom escuro ao preto, com as margens inteiras em marrom claro, o pericarpo de textura lenhosa. Pedúnculo com 7,5 mm de compr., sublenhoso, estriado, cálice persistente e rígido, puberulento, tricomas adpressos, marrons claros (Figura 2B). Legume reto ou encurvado (Figura 2C), faces suavemente onduladas, nervuras transversais levemente elevadas, seco, deiscente (Figura 2D).

Ápice acuminado-apiculado (Figura 2E), apículo de cerca de $5 \mathrm{~mm}$ de compr., base cuneado-atenuada, sub-estipitada (Figura 2F), estipe espessado, tricomas semelhantes aos do pedúnculo, margens inteiras, constrictas, nervuras dorsal e ventral caracterizadas por uma linha rígida e saliente que vão da base ao ápice do fruto.

A deiscência (abertura) inicial das valvas é pela base do fruto e progride ao longo das suturas. Placentação marginal, polispérmico, com 20 a 39 sementes, e média de 33 sementes por fruto, distribuídas em uma série. Os frutos apresentaram valores médios de 12,96 cm de comprimento, $1,45 \mathrm{~cm}$ de largura e 0,22 de espessura, conforme apresentado na Tabela 1, bem como os demais valores de amplitude, desvio padrão e coeficiente de variação. 
Figura 2. Frutos de matapasto (S. reticulata). A - Legumes maduros. B - Fruto em vista lateral, com curvatura. C - Fruto aberto com sementes e reto. D - Fruto com curvatura, de vista frontal. E - Ápice do fruto. F - Base do fruto. Legendas: (ap) apículo, (est) estipe, (ncd) nervura carpelar dorsal, (pd) pedúnculo.

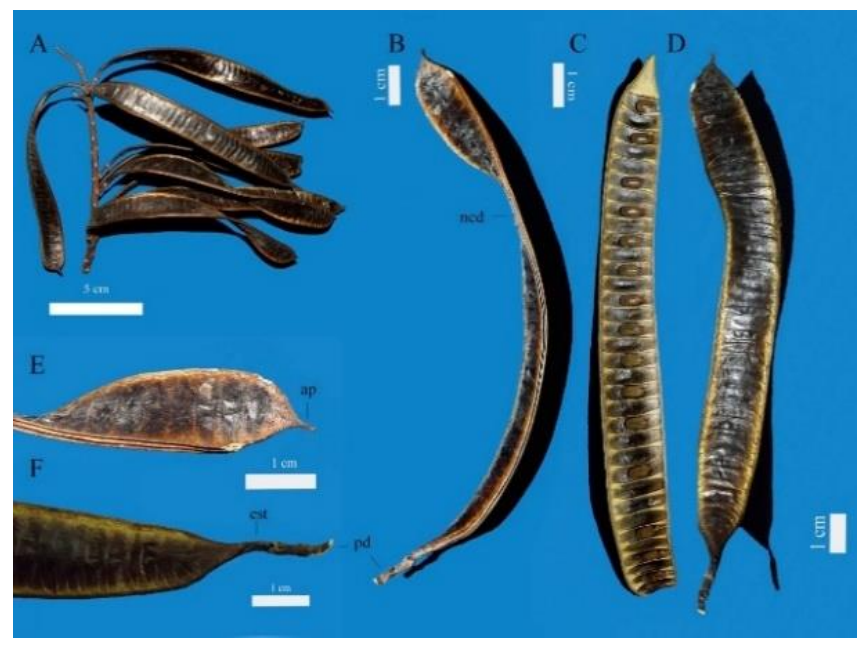

Fonte: Autores.

Tabela 1. Características biométricas de frutos e sementes de matapasto (S. reticulata): valores de mínima, máxima, média, desvio padrão $(\sigma)$ e coeficiente de variação $(\mathrm{CV})$ do comprimento, largura e espessura (frutos em $\mathrm{cm}$ e sementes em $\mathrm{mm})$.

\begin{tabular}{lccccc}
\hline \multicolumn{1}{c}{ Determinações } & Média & $\Sigma$ & Mínima & Máxima & CV $(\%)$ \\
\hline Comprimento do fruto $(\mathrm{cm})$ & 12,96 & 0,75 & 10,46 & 16,59 & 5,79 \\
Largura do fruto $(\mathrm{cm})$ & 1,45 & 0,06 & 1,32 & 1,60 & 3,92 \\
Espessura do fruto $(\mathrm{cm})$ & 0,22 & 0,03 & 0,17 & 0,29 & 11,84 \\
Comprimento da semente & 6,42 & 0,24 & 5,74 & 6,95 & 3,82 \\
$(\mathrm{~mm})$ & & & & & \\
Largura da semente $(\mathrm{mm})$ & 2,32 & 0,12 & 1,78 & 2,76 & 5,38 \\
Espessura da semente $(\mathrm{mm})$ & 1,74 & 0,11 & 1,42 & 2,23 & 6,63 \\
\hline
\end{tabular}

Fonte: Autores.

\section{Biometria de sementes}

A partir deste estudo foi verificado que as sementes de matapasto ( $S$. reticulata) apresentaram valores médios de 12,96 mm de comprimento, 2,32 mm de largura e 1,74 de espessura (Tabela 1). Segundo Rodrigues et al. (2015), os valores das dimensões de frutos e sementes podem fornecer informações necessárias para a seleção de sementes de maior tamanho e massa, uma vez que ter noções para este critério contribui para maiores êxitos em testes de germinação e vigor de espécies.

Foi observado que as sementes apresentaram formato elipsoide (Figura 3A), de perfil apresenta-se transversalmente rômbica (Figura 3B), ápice proeminente (Figura 3C), margem inteira, base arredondada-cuneada. A região hilar (Figura 3C) sub-basal, hilo orbicular, heterócromo, enegrecido, em depressão, circundado pela bordadura hilar marrom mais escuro que a testa, lente visível e elevada, como duas proeminências laterais, heterócroma, região central marrom mais clara que o hilo, abaixo observa-se um arredondamento caracterizando o contorno da radícula, rafe heterócroma, marrom mais claro que o hilo. 
Figura 3. Morfologia de sementes de matapasto (S. reticulata). A - Sementes elipsoides. B - Sementes em vista lateral, hidratada (acima) e desidratada (abaixo). C - Vista evidenciando hilo e lente. D - Semente hidratada em secção transversal. E Embrião foliáceo. F - Secção transversal. G - Eixo embrionário reto. H - Eixo embrionário. Legendas: (bh) bordadura hilar, (cr) contorno da radícula, (ct) cotilédones, (ed) endosperma, (ee) eixo embrionário, (h) hilo, (le) lente, (prd) pólo radicular e (pr) pleurograma.

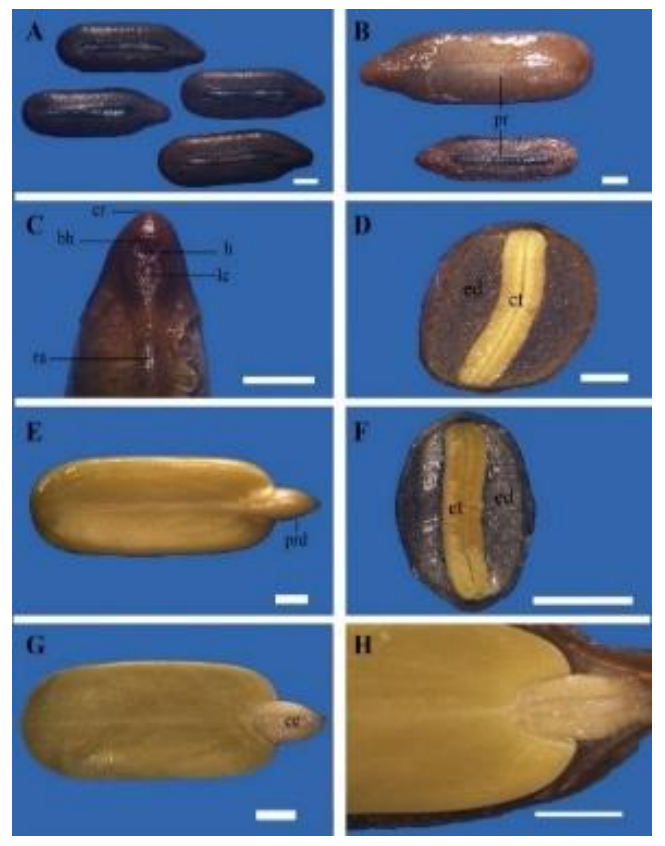

Fonte: Autores.

A camada interna do tegumento é marrom escura e membranácea (Figura 3D), endosperma contínuo, hialino e vítreo (desidratado) (Figura 3F), mucilaginoso e marrom claro (hidratado) (Figura 3D), mais espesso nas laterais e adnato ao tegumento. O embrião (Figura 3E) é axial e foliáceo, amarelo, dominante, oblongo, ápice arredondado, margem inteira, base arredondada, lâminas retas com as faces superiores em contato, entalhado, unidos somente ao ápice do eixo hipocótiloradícula. Eixo embrionário (Figura 3G) reto entre os lóbulos cotiledonares, obcônico, espesso, amarelo, plúmula indiferenciada (Figura 3H).

O tegumento desidratado apresenta duas colorações distintas, marrom escuro do pericarpo e preto, observado em ambas as faces, pleurograma é completo estreito e linear, em secção é pétreo (Figura 3F). Quando hidratado o tegumento (Figura 3B) é praticamente monocrômico, se tornando marrom, inclusive o pleurograma. A presença de pleurograma é rara, mas de grande ajuda no reconhecimento de espécies através das sementes, uma vez que ocorre somente nas famílias Cucurbitaceae e Leguminosae, subfamília Mimosoideae e em algumas espécies da subfamília Caesalpinioideae (Gunn, 1991), é praticamente restrita aos gêneros Cassia e Senna, apresentando-se completo (Barroso et al., 1999).

\section{Teor de água e peso de mil sementes}

O teor de umidade para as sementes de matapasto (S. reticulata) observado através deste estudo foi de 9,9\%, o que é considerado baixo segundo Marcos-Filho (2015), e confirma que a espécie não apresenta comportamento recalcitrante, ou seja, suas sementes podem ser armazenadas por longos períodos sem que haja perdas significativas de viabilidade para o seu processo germinativo. No entanto, são necessários maiores estudos sobre o tema, para confirmar o período e valores exatos que este e demais fatores influenciam em sua capacidade germinativa. 
O peso de mil sementes para matapasto (S. reticulata) obtido neste estudo realizado em Belém-PA (Amazônia Oriental) foi de 19 gramas, que difere em comparação aos dados obtidos por Souza et al. (2012) que obteve o valor de 14 gramas para a mesma espécie, porém noutra região amazônica (Manacapuru, AM - Amazônia Central). Tal diferença pode ocorrer devido às diferenças ambientais, bem como devido a fatores relacionados à genética de populações, pois Lima et al. (2015) através de estudos genéticos em populações geograficamente próximas de matapasto ( $S$. reticulata) na Amazônia observou que há consideráveis variações. Sendo assim, é interessante o estudo dessas e demais características da espécie, mesmo em diferentes ambientes, para apresentação de informações que auxiliem na composição de lotes e outras formas de agrupamento de sementes.

\section{Germinação}

Após análise da germinação de matapasto (S. reticulata) (Figura 4), foi observada que esta ocorre a partir do segundo dia, e a taxa de germinação é superior a $50 \%$ após o $5^{\circ}$ dia de plantio, chegando até $100 \%$ ao $82^{\circ}$ dia após o plantio.

Figura 4. Germinação de matapasto (S. reticulata). Cuja equação foi y $=0.6399 \mathrm{x}+54.005, \mathrm{R}^{2}=0.6523$.

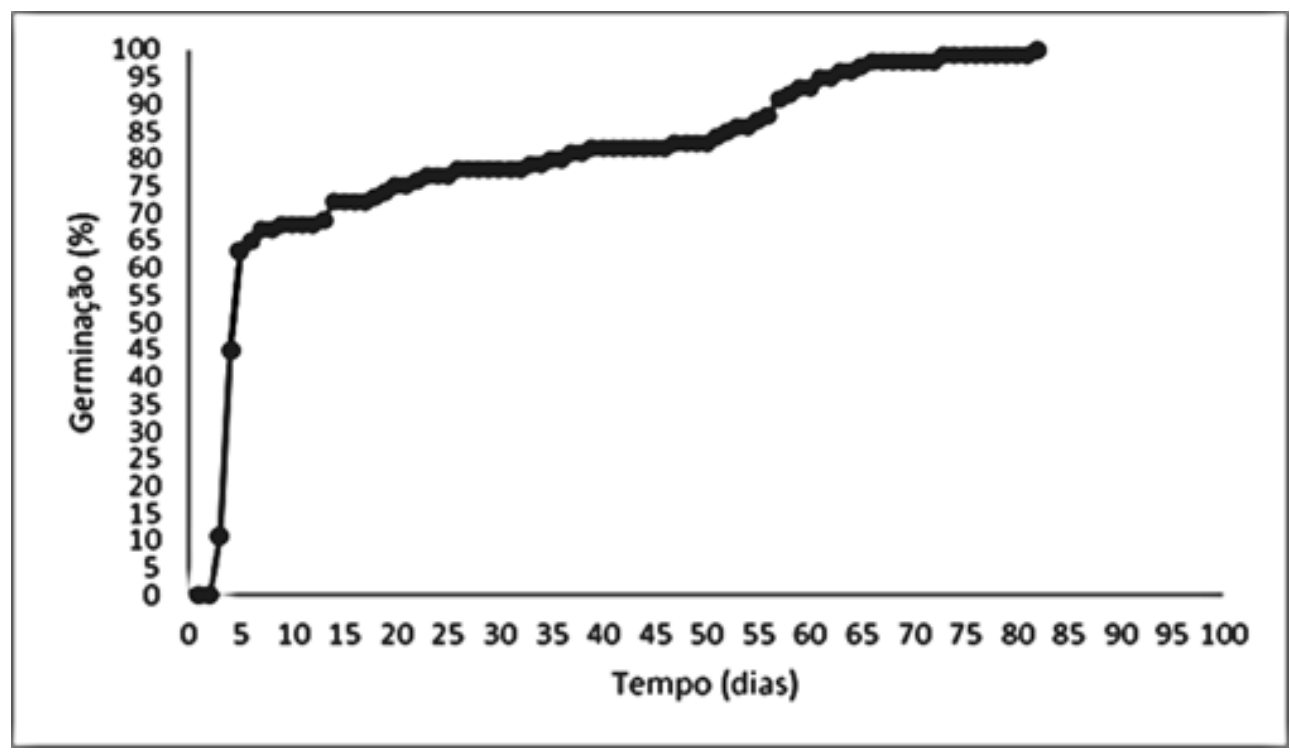

Fonte: Autores.

Souza (2012) analisando a germinação de matapasto (S. reticulata) em Manacapuru-AM (Amazônia Central), também obteve altos índices de germinação (97\%). O trabalho feito por Parolin (2001) com a espécie em Manaus (AM) e ambientes de várzea na Amazônia, indica que esta espécie é rústica e adaptável. Sendo assim, o matapasto ( $S$. reticulata) é uma espécie de uso recomendável para questões de reflorestamento, devido esta apresentar alto índice de germinação, além das diversas características úteis da espécie como seu uso alimentício, ornamental e medicinal. Além de que a espécie além de auxiliar na recomposição de áreas, pode gerar fontes de renda através do seu plantio para fins comerciais.

\section{Desenvolvimento até estágio de planta jovem}

Foi observado neste estudo o desenvolvimento de matapasto ( . reticulata), desde sua germinação, passando pelo estágio de plântula (com folhas primitivas) até a formação da planta jovem (com folhas definitivas) (Figura 5). Sendo a fase de planta jovem a ideal para plantio, pois a espécie já apresenta as características foliares de um indivíduo adulto a partir de 33 dias de plantio, sendo assim, as mudas estão prontas para serem replantadas em ambientes onde poderão se desenvolver. 
A semente intumesce a partir do $1^{\circ}$ dia de plantio (Figura 6A). Em seguida rompe o tegumento, com a protrusão da raiz primária (Figura 5B). Ocorre alongamento da raiz, com diferenciação da alça hipocotilar (Figura 5C), e de acordo com a definição de Brasil (2009a), este tipo de germinação é do tipo fanerocotiledonar epígea (Figura 5C). O coleto é identificável apenas por uma leve diferença de cor entre a raiz e o hipocótilo marrom-escuro (Figura 5D). Em seguida, o hipocótilo alongase elevando acima do nível do solo e os cotilédones com o tegumento ainda persistente no ápice (Figura 5E). Os cotilédones vão sendo liberados do tegumento ainda amarelados (Figura 5F). Ocorre a expansão dos cotilédones e surgimento do primeiro eófilo (folha primária) (Figura 5G) e, posteriormente, há expansão do eófilo, revelando este ser composto por dois folíolos (Figura $5 \mathrm{H}$ ). Ao $33^{\circ}$ dia após o plantio há o surgimento do metáfilo (folha adulta), composto por quatro folíolos.

Figura 5. Desenvolvimento de mata-pasto (S. reticulata). A - Semente intumescida; B - Protrusão da raiz. C - Emergência e alongamento da raiz primária. D - Elevação dos cotilédones. E - Cotilédones ainda presos pelo tegumento. F - Cotilédones totalmente livres. G - Plântula com eófilo e raízes laterais. H - Eófilo totalmente formado. I - Planta jovem (aos 33 dias). Legendas: cl - coleto; ct - cotilédone; ep - epicótilo; hp - hipocótilo; rd - radícula; rp - raiz primária; rl - raiz lateral; tg tegumento.

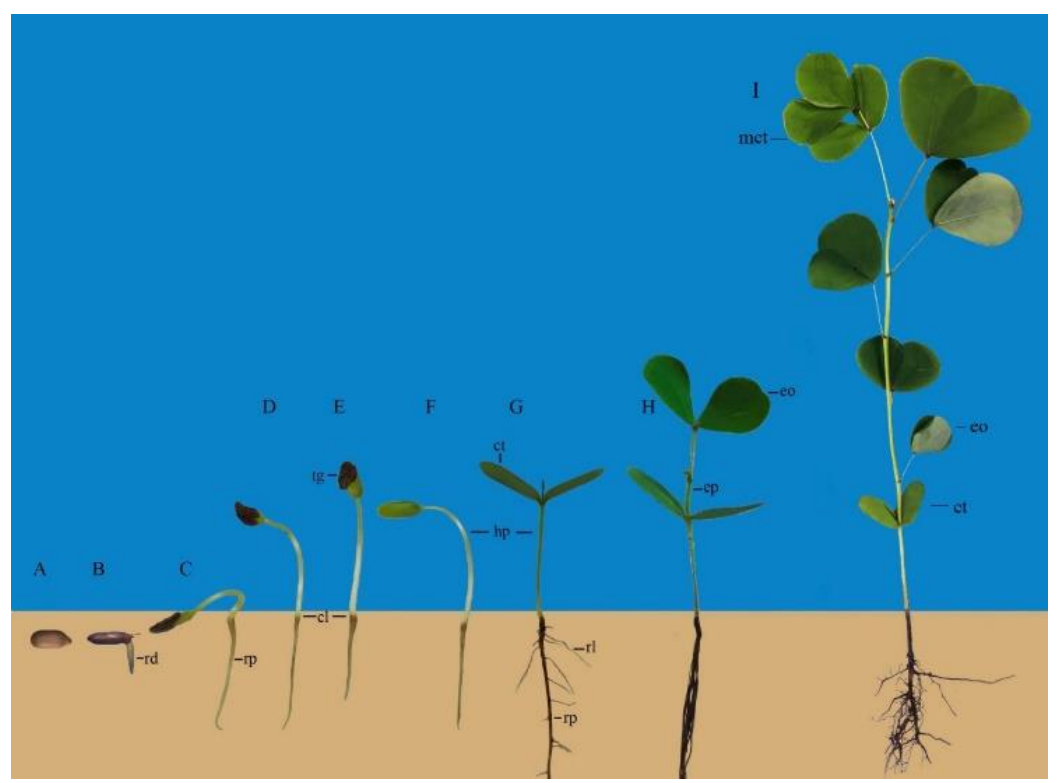

Fonte: Autores.

\section{Conclusão}

Através deste estudo foi observado as sementes de matapasto ( $S$. reticulata) apresentam médias de 6,42 mm de comprimento.; 2,32 mm de largura; e 1,74 mm de espessura. A germinação começa a partir do $2^{\circ}$ dia de plantio, do tipo fanerocotiledonar, a planta jovem forma-se a partir dos 33 dias, caracterizada por apresentar metáfilo com quatro folíolos.

\section{Agradecimentos}

Agradecemos ao Museu Paraense Emílio Goeldi (MPEG) pela infraestrutura e apoio, fundamentais para o desenvolvimento deste trabalho. Ao Programa de Pós-Graduação em Biodiversidade e Biotecnologia da Amazônia Legal REDE BIONORTE. À CAPES e ao CNPq. E todos que de alguma forma colaboraram com o desenvolvimento desta pesquisa. 


\section{Referências}

Albuquerque, J. M. (1993). Identificação e germinação de sementes amazônicas. FCAP. 132p.

Barroso, G. M., Morin, M. P., Peixoto, A. L. \& Ichaso, C. L. F. (1999). Frutos e sementes: morfologia aplicada à sistemática de dicotiledôneas. UFV. 443p.

Brasil. (2009a). Glossário ilustrado de morfologia. Ministério da Agricultura, Pecuária e Abastecimento do Brasil. 406p. <https://www.gov.br/agricultura/ptbr/assuntos/insumos-agropecuarios/arquivos-publicacoes-insumos/10829_glossario_ilustrado_morfologia-3.pdf >.

Brasil. (2009b). Manual de análise sanitária de sementes. Ministério da Agricultura, Pecuária e Abastecimento do Brasil. 200p. https://www.gov.br/agricultura/pt-br/assuntos/insumos-agropecuarios/insumos-agricolas/sementes-e-mudas/publicacoes-sementes-e-mudas/manual-de-analisesanitaria-de-sementes>.

Brasil. (2009c). Regras para análise de sementes. Ministério da Agricultura, Pecuária e Abastecimento do Brasil. 399p. <https://www.gov.br/agricultura/ptbr/assuntos/insumos-agropecuarios/arquivos-publicacoes-insumos/2946_regras_analise_sementes.pdf >.

Brasil. (2013). Instruções para análise de sementes de espécies florestais. Ministério da Agricultura, Pecuária e Abastecimento do Brasil. 97p. < https://www.gov.br/agricultura/pt-br/assuntos/laboratorios/arquivos-publicacoes-laboratorio/florestal_documento_pdf-ilovepdf-compressed.pdf>.

Camargo, J. L. C., Ferraz, I. D. K., Mesquita M. R., Santos, B. A. \& Brum, H. D. (2008). Guia de propágulos e plântulas da Amazônia. Instituto Nacional de Pesquisas da Amazônia. 168p.

Coelho Junior, L. M., Nunes, A. M. M., Pádua, J. F. F., Santos Júnior E. P. \& Lima, P. A. F. (2020). O desenvolvimento brasileiro das florestas de rápido crescimento com fins energéticos. Brazilian Journal of Development. 6(5), 28111-28125. https://doi.org/10.34117/bjdv6n5-310

Deuber, R. (2003). Ciência das plantas infestantes. FUNEP. 32-49.

Di Stasi, L. C. \& Hiruma-Lima, C. A. (2002). Plantas medicinais na Amazônia e na Mata Atlântica. UNESP. 282-283. < http://www.dominiopublico.gov.br/download/texto/up000036.pdf>.

Falcão-Da-Silva, M., Souza Filho, A. P. S., Gurgel, E. S. C., Bastos, M. N. C. \& Santos, J. U. M. (2016). Plantas daninhas na Amazônia. Museu Paraense Emílio Goeldi. Páginas 94-95.

FAO - Food and Agriculture Organization of the United Nations. <https://www.fao.org/fruits-vegetables-2021/en/>.

Farias, J. R. B., Nepomuceno, A. L., Neumaier, N. (2007). Ecofisiologia da soja. Embrapa. https://www.infoteca.cnptia.embrapa.br/handle/doc/470308

Forzza, R. C., Baumgratz, J. F. A., Bicudo, C. E. M., Dora, A. L., Carvalho Jr, A. A., Coelho, M. A. N., Costa, A. F., Costa, D. P., Hopkins, M. G., Leitman, P. M., Lohmann, L. G., Lughadha, E. N., Maia, L. C., Martinelli, G., Menezes, M., Morim, M. P., Peixoto, A. L., Pirani, J. R., Prado, J., Queiroz, L. P., Souza, S., Souza, V. C., Stehmann, J. R., Sylvestre, L. S., Walter, B. M. T. \& Zappi, D. (2012). New Brazilian Floristic List Highlights Conservation Challenges. BioScience, 62(1), 39-45. https://doi.org/10.1525/bio.2012.62.1.8

Gomes, V. H. F., Vieira, I. C. G., Salomão, R. P. \& Ter Steege, H. (2019). Amazonian tree species threatened by deforestation and climate change. Nature Climate Change, 9, 547-553. DOI: https://doi.org/10.1038/s41558-019-0500-2

Grandis, A., Arenque-Musa, B. C., Martins, M. C. M., Maciel, T. O., Simister, R., Gómez, L. D., Buckeridge, M. S. (2021). Senna reticulata: a Viable Option for Bioenergy Production in the Amazonian Region. BioEnergy Research, 14, 91-105. DOI: https://doi.org/10.34117/bjdv6n5-310

Gunn, C. R. (1991). Fruits and seeds of genera in the Subfamily Caesalpinioideae (Fabaceae). United States Department_of Agriculture. Agricultural Research Service, Springfield. Technical Bulletin. 408p.

Gurgel, E. S. C. (2009). Morfoanatomia, Perfil Químico e Atividade Alelopática de três Espécies de Copaifera L. (Leguminosae, Caesalpinoideae) Nativas da Amazônia. (Tese de Doutorado) Instituto Nacional de Pesquisas da Amazônia e Universidade Federal do Amazonas. 107p.

Gurgel, E. S. C., Falcão-Da-Silva, M., Lucas, F. C. A., Carreira, L. M. M. \& Santos, J. U. M. (2014). Morfologia do fruto e da semente de três espécies de Senna Mill. (Leguminosae - Caesalpinioideae). Biota Amazônia, 4(2), 80-86. http://dx.doi.org/10.18561/2179-5746/biotaamazonia.v4n2p80-86

Gurgel, E. S. C., Oliveira, M. S., Souza, M. C., Silva, S. G., Mendonça, M. S. \& Souza Filho, A.P.S. (2019). Chemical compositions and herbicidal (phytotoxic) activity of essential oils of three Copaifera species (Leguminosae-Caesalpinoideae) from Amazon-Brazil. Industrial Crops and Products, 142, 111850. 10.1016/J.INDCROP.2019.111850

IBGE - Instituto Brasileiro de Geografia e Estatística. (2014). Contas de ecossistema: espécies ameaçadas de extinção no Brasil. < https://biblioteca.ibge.gov.br/visualizacao/livros/liv101754_folder.pdf >.

Irwin, H. S. \& Barneby, R. C. (1982). The American Cassiinae: A Synoptical Revision of Leguminosae Tribe Cassieae subtribe Cassinae in the New World Memoirs of The New York Botanical Garden. 35, 10-12.

Lorenzi, H. \& Matos, F. J. A. (2021). Plantas medicinais no Brasil. (3a ed.), Jardim Botânico Plantarum. 576p.

Lima, R. A. D., Lopes, M. T. G., Bentes, J. L. D. S., Valente, M. S. F., Pereira, J. O., Muniz, G. I. B. D. (2015). Diversidade e estrutura genética de Senna reticulata. FLORESTA, 45(3),507-514. http://dx.doi.org/10.5380/rf.v45i3.38079

Macedo, S. E. M., Alan, E., Silva, J. G. \& Silva, M. G. V. (2016). Quimiodiversidade e Propriedades Biofarmacológicas de Espécies de Senna Nativas do Nordeste do Brasil. Revista Virtual de Química, 8(1) 169-195. http://static.sites.sbq.org.br/rvq.sbq.org.br/pdf/v8n1a13.pdf

Marcos-Filho, J. (2015). Fisiologia de sementes de plantas cultivadas. ABRATES. 659p. 
Research, Society and Development, v. 10, n. 17. e245101724807, 2021

(CC BY 4.0) | ISSN 2525-3409 | DOI: http://dx.doi.org/10.33448/rsd-v10i17.24807

Martins-da-Silva, R. C. V., Silva, A. S. L., Fernandes, M. M. \& Margalho, L. F. (2014). Noções morfológicas e taxonômicas para identificação botânica. Embrapa. 111p. <https://www.embrapa.br/busca-de-publicacoes/-/publicacao/992543/nocoes-morfologicas-e-taxonomicas-para-identificacao-botanica>.

Ministério do Meio Ambiente - MMA. (2021). Biodiversidade brasileira. <https://antigo.mma.gov.br/biodiversidade/biodiversidade-brasileira.html>

Moura, R. C., Lopes, P. S. N., Brandão Junior, D. S., Gomes, J. G. \& Pereira, M. B. (2010). Biometria de frutos e sementes de Butia capitata (Mart.) Beccari (Arecaceae), em vegetação natural no Norte de Minas Gerais. Brasil. Biota Neotropica, 10(2), 415-419. https://doi.org/10.1590/S1676-06032010000200040

Mourão, K. S. M., Domingues, L. \& Marzinek, J. (2007). Morfologia de plântulas e estádios juvenis de espécies invasoras. Acta Scientiatum Biological Sciences, 29(3), 261-268. https://doi.org/10.4025/actascibiolsci.v29i3.475

Parolin, P. (2001). Senna reticulata, a Pioneer Tree from Amazonian Várzea Floodplains. Botanical Review, 67(2), 239-254. 10.1007/BF02858077

Neves, A. M., Costa, P. S., Coutinho, M. G. S., Souza, E. B., Santos, H. S., Silva, M. G. V. \& Fontenelle, R. O. S. (2017). Caracterização química e o potencial antimicrobiano de espécies do gênero Senna Mill. (Fabaceae). Revista Virtual de Química, 9(6), 2506-2538. 10.21577/1984-6835.20170149

Prance, G. T. (1975). Árvores de Manaus. Instituto Nacional de Pesquisas da Amazônia. 141-142.

Rodrigues, J. K., Mendonça, M. S. \& Gentil, D. F. O. (2015). Aspectos biométricos, morfoanatômicos e histoquímicos do pirênio de Bactris maraja (Arecaceae). Rodriguésia, 66(1), 075-085. https://doi.org/10.1590/2175-7860201566105

Rodrigues, R. M. (1989). A FLORA DA AMAZÔNIA. CEJUP. 136-137.

Santos, R. N. C, Silva, M.G.V. \& Braz Filho, R. (2008). Constituintes químicos do caule de Senna reticulata Willd. (Leguminoseae). Química Nova. 31(8):1979-1981. https://doi.org/10.1590/S0100-40422008000800011

Silva, F. W. A., Gurgel, E. S. C., Cruz, E.D. \& Santos, J. U. M. (-2016). Morfologia do fruto, da semente, da plântula e da planta jovem de Sarcaulus brasiliensis A. DC. Eyma (Sapotaceae). Biota Amazônia. 6(3), 7-11. http://dx.doi.org/10.18561/2179-5746/biotaamazonia.v6n3p7-11

Silva, M. J., Santos, J. P. \& Souza, A. O. (2018). Sinopse taxonômica do gênero Senna (Leguminosae, Caesalpinioideae, Cassieae) na Região Centro-Oeste do Brasil. Rodriguésia. 69(2), 733-763. https://doi.org/10.1590/2175-7860201869233

Souza, L. A. G. (2012). Leguminosas para adubação verde na terra firme e na várzea da Amazônia Central: um estudo em pequenas propriedades rurais em Manacapuru. Instituto Nacional de Pesquisas da Amazônia. 22-23.

Souza, V. C. \& Bortoluzzi, R. L. C. (2021). Senna in Lista de Espécies da Flora do Brasil. Jardim Botânico do Rio de Janeiro. <http://floradobrasil.jbrj.gov.br/jabot/floradobrasil/FB23167>.

Tropicos. (2021). Base de dados do Missouri Botanical Garden. 〈http://www.tropicos.org>.

Willdenow, C. L. (1809). Enumeratio Plantarum Hortiregii Botanici. 443. < https://www.biodiversitylibrary.org/item/275519\#page/459/mode/1up>. 